\title{
Micropuncture Study of Fluid Transfer in Aminonucleoside Nephrosis in the Rat
}

\author{
JOHN E. LEWY 28$\rangle$ \\ Division of Pediatric Nephrology, Department of Pediatrics, Cornell University Medical College, \\ New York, New york, USA
}

\section{Extract}

The relationship between glomerular filtration rate and proximal tubular fluid reabsorption was evaluated in control rats and in rats 96 and $144 \mathrm{hr}$ after the injection of an aminonucleoside of puromycin. Urine volume and sodium excretion were decreased in the rats injected with aminonucleoside. Proteinuria increased progressively. Total kidney glomerular filtration rate (GFR) was diminished less than surface nephron GFR at $96 \mathrm{hr}$ and greater than single nephron GFR at $\mathbf{1 4 4} \mathrm{hr}$ after injection when a large proportion of nephrons are nonfunctional. Clearance of $p$-aminohippurate was unchanged initially and depressed subsequently after aminonucleoside injection. Absolute reabsorption to the end of the proximal convolution was unaltered despite a decrease in total kidney filtration fraction. This decrease in GFR coupled with unchanged absolute reabsorption and hence increased fractional proximal reabsorption leads to decreased delivery of sodium and fluid to the more distal portions of the nephron.

\section{Speculation}

Glomerular filtration rate is decreased in rats with aminonucleoside nephrosis. Absolute reabsorption along the proximal tubule is not reduced proportionally. The increase in fractional reabsorption which results coupled with a decrease in GFR may be an important source of fluid and sodium retention and thus edema formation in this disease.

Since Frenk et al. (7) reported in 1955 that an aminonucleoside of puromycin (AMN) was capable of regularly producing the nephrotic syndrome in the rat, this animal model has served as a useful model to study mechanisms of proteinuria and edema formation. Edema formation in this disease is a complex interaction of multiple factors (17). However, most investigators have directed their attention to the influence of absolute or relative glomerular insufficiency, tubular preponderance, and hormonal control of sodium and water reabsorption. Edema formation can occur in the absence of aldosterone $(11,12,23)$. In a study by Herken et al. (11), intact and adrenalectomized rats with AMN nephrosis, infused orally with isotonic saline, showed decreased GFR and decreased sodium excretion, as well as increased fractional sodium reabsorption. The question of the relative importance of decreased glomerular filtration and increased tubular reabsorption of sodium and water thus was raised in the animal model. Godon (8) has demonstrated recently that saline loading fails to reduce fractional sodium reabsorption in rats with glomerulonephritis produced by immunization with glomerular basement membrane. Rocha and coworkers (20) showed increased fractional reabsorption of sodium from the proximal tubule of rats with glomerulonephritis but found that fractional reabsorption of sodium and fluid along the entire nephron was unaltered from that of controls. Decreased GFR resulted in decreased absolute sodium excretion.
The present study was designed to assess the relationship between glomerular filtration and proximal tubular reabsorption of sodium and fluid in AMN nephrosis. Micropuncture methods were employed to evaluate changes in single nephron glomerular filtration rate, absolute rates of fluid reabsorption, fractional fluid reabsorption, intratubular pressures, and passage time along the proximal convolution. The data suggest that a decrease in the quantity of glomerular filtrate not accompanied by a proportional diminution in absolute proximal reabsorption leads to retention of fluid. This occurs despite a decrease in filtration fraction, and without changes in proximal tubular hydrostatic pressure.

\section{METHODS}

Nephrosis was produced in male Sprague-Dawley albino rats, weighing $150-250 \mathrm{~g}$, by the intravenous administration of $10 \mathrm{mg} /$ $100 \mathrm{~g}$ body wt of 6-dimethyl-9-(3'-amino-3'-deoxy- $\beta$-D-ribofuranosyl) purine. After the intravenous injection of aminonucleoside (saline in controls) into the tail vein, the animals were placed in individual balance cages and their weights, urinary output, and protein excretion monitored daily. Controls were pair-fed. The last $12 \mathrm{hr}$ before renal function was to be studied, the animals were given no food but received water ad libitum. The data of urinary output and urinary protein excretion represent this $12-\mathrm{hr}$ period in the unanesthetized rat (Table 1). Initial studies were performed in animals 3, 4, and 6 days after the injection of the aminonucleoside of puromycin and in pair-fed controls. Three days after AMN injection there was no proteinuria. By 4 days a morphologic and biochemical lesion was identifiable $(24,25)$. Proteinuria had begun, but was mild (13). There had been no weight gain and no observable edema, although sodium excretion was diminished. There was no ascites and inspection of the kidney revealed that surface nephrons were uniform in appearance. In contrast, the 6-day animal had marked ascites and surface tubules were markedly variable in appearance and function (13). Sodium retention and proteinuria were considerably increased.

Micropuncture techniques were employed to study single nephron function in animals 96 and $144 \mathrm{hr}$ after the injection of aminonucleoside and in controls. The animals were anesthetized by an intraperitoneal injection of $80-100 \mathrm{mg} / \mathrm{kg}$ body weight of Inactin. The left and right external jugular veins were cannulated as was the trachea. The animal was placed on a heated animal table and a flank incision was made. The left kidney was exposed and freed from the adrenal gland and perirenal fat by blunt dissection. The renal capsule was left intact. The kidney was placed in a lucite cup, in vivo, and covered with a continuous drip of light mineral oil, warmed to $37-38^{\circ}$. The ureter was cannulated. Physiologic saline ( $1 \%$ of body weight) was injected slowly intravenously to replace surigcal fluid losses, followed by a continuous infusion of saline at a rate of $0.01 \mathrm{ml} / \mathrm{min}$. This fluid contained ${ }^{14} \mathrm{C}$-labeled inulin and $p$-aminohippurate $(\mathrm{PAH})$ in sufficient quantities to deliver $30 \mu \mathrm{Ci}\left[{ }^{14} \mathrm{C}\right]$ inulin $/ \mathrm{hr}$ and to sustain a 
Table 1. Whole kidney function and excretion ${ }^{1}$

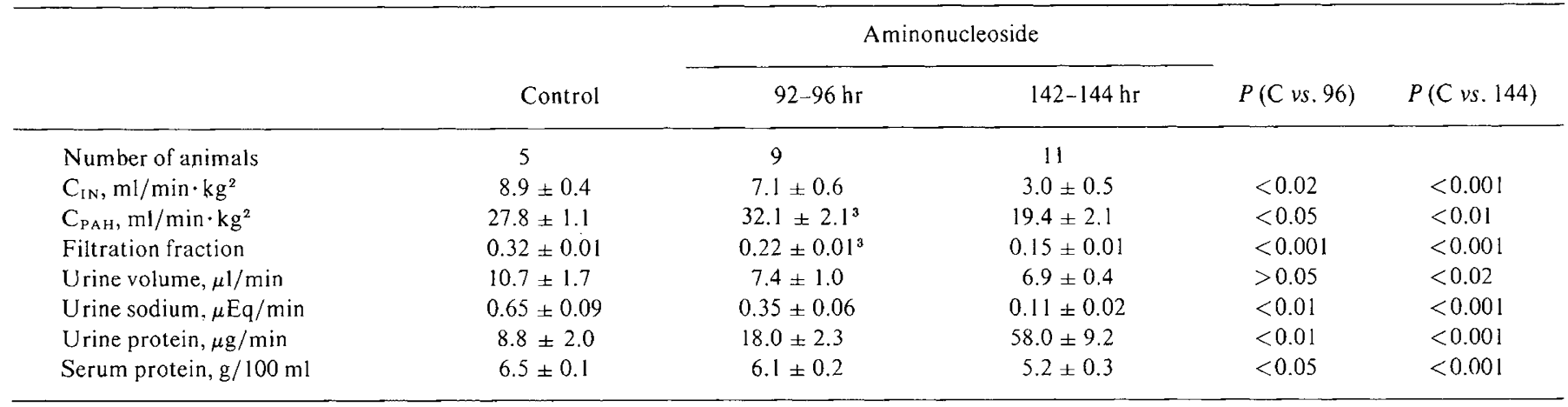

${ }^{1}$ Data are expressed as mean $\pm \mathrm{SEM}$.

${ }^{2}$ Two or more observations were made on each animal.

${ }^{3}$ Observations made on seven animals.

plasma level of PAH of $3-5 \mathrm{mg} / 100 \mathrm{ml}$. At least $30 \mathrm{~min}$ were allowed for equilibration in extracellular fluid before beginning collections. Serial clearance periods were obtained throughout the experiment. Blood samples (approximately $100 \mu \mathrm{l}$ ) were taken from the tail vein.

Overall renal function was measured, including inulin clearance $\left(\mathrm{C}_{\mathrm{IN}}\right)$, PAH clearance $\left(\mathrm{C}_{\mathrm{PAH}}\right)$, and extraction of $\mathrm{PAH}$ $\left(E_{p_{A H}}\right)$. Serum protein concentration was also estimated.

Free-flow micropuncture was performed with micropipettes with tips of 10-12 $\mu \mathrm{m}$ (outside diameter). Light mineral oil, stained with Sudan black, was used to block the tubule distal to the site of collection. Intratubular pressure was measured manometrically with a Gauer mercury manometer following the technique as described by Wirz (26) and Gottschalk and Mylle (10). Proximal fluid transit time was taken as the time between diffuse coloration of the kidney surface and appearance of the dye in the tip of the collecting pipette (22). The end of the proximal convolution was chosen in all free-flow micropunctures where absolute reabsorption was measured. This site was selected by observing lissamine green passage to a group of tubules surrounding an efferent arteriole, its tributaries arranged in a "star formation." This has been found by microdissection to correspond to $52-65 \%$ of the total proximal tubular length in $95 \%$ of cases (19).

Glomerular filtration rate of individual nephrons, absolute rate of fluid reabsorption, and transit time, were measured in the same tubule. Individual nephron GFR and absolute rate of fluid reabsorption to the point of puncture were calculated from the rate of fluid collection in the micropipette and the tubular fluidto-plasma inulin concentration ratio $\left(\mathrm{TF} / \mathrm{P}_{\text {inulin }}\right)$. Great care was taken to obtain quantitative collections. Samples were discarded when fluid accumulated on the kidney surface around the micropipette, when the oil block moved distally, or when spontaneous free inflow into the micropipette ceased.

Individual tubular and overall GFR were estimated with $\left[{ }^{14} \mathrm{C}\right]$ inulin carboxylic acid, analyzed in a Packard Tri-Carb liquid scintillation counter. Total renal plasma flow was estimated by measuring PAH clearances. p-Aminohippurate was analyzed colorimetrically by the method of Bratten and Marshall as modified by Smith (9). Protein in serum and urine was estimated by a modification of the method of Lowry (15). Statistical differences were tested using Student's $t$ distribution.

\section{RESULTS}

Table 1 illustrates overall data for those rats for which individual nephron measurements during free flow were obtained. GFR, as measured by inulin clearance, decreased significantly from 8.9 in controls to $7.1 \mathrm{ml} / \mathrm{min} \cdot \mathrm{kg}(-21 \%)$ at 4 days and to $3.0 \mathrm{ml} /$ min. $\mathrm{kg}(-66 \%)$ at 6 days after injection of AMN. PAH clearance increased slightly but significantly from 27.8 to $32.1 \mathrm{ml} /$ $\mathrm{min} \cdot \mathrm{kg}$ at 4 days and decreased to $19.4 \mathrm{ml} / \mathrm{min} \cdot \mathrm{kg}(-30 \%)$ in the 6-day rats. $\mathrm{C}_{\mathrm{PAH}}$ reflects a constant proportion of renal plasma flow at least early in the disease since $E_{\text {PAH }}$ was $70.5 \pm 1.4 \%$ in four control animals and $69.8 \pm 1.3 \%$ in four 4-day rats. The filtration fraction $\left(\mathrm{C}_{\mathrm{IN}} / \mathrm{C}_{\mathrm{PAH}}\right)$ was thus diminished from 0.32 to 0.22 at 4 days and to 0.15 at 6 days. Urine volume during the last $12 \mathrm{hr}$ on balance was slightly diminished in the AMN animals. Urine sodium was measured in aminonucleoside rats during the $12 \mathrm{hr}$ before the micropuncture study and in pair-fed controls. Sodium excretion was $0.35 \pm 0.06 \mu \mathrm{Eq} / \mathrm{min}$ in 4 day AMN rats and $0.65 \pm 0.09 \mu \mathrm{Eq} / \mathrm{min}$ in the control rats $(P<0.01)$. The fully nephrotic rats sodium excretion was 0.11 $\mu \mathrm{Eq} / \min (P<0.01)$. Urine protein excretion increased significantly in AMN animals. Total serum protein was diminished slightly (Table 1).

Table 2 tabulates observations in individual nephrons in the same animals. GFR in control rats averaged $32.6 \mathrm{nl} / \mathrm{min}$ and was reduced $36 \%$ in 4-day aminonucleoside animals. Absolute reabsorption to the end of the proximal convolution, on the other hand, was essentially unaltered from control levels despite the reduction of GFR. Fractional reabsorption, as illustrated by $\mathrm{Tf} / \mathrm{P}$ inulin ratios measured at the end of the proximal convolution, was thus increased from a mean of 1.84 in control to 2.85 in 4-day aminonucleoside rats. In the 6-day rats at least two populations of surface tubules were apparant. Fifty to $70 \%$ of the nephrons appeared to be normal in size. These had a GFR averaging $21.4 \mathrm{nl} / \mathrm{min}$ and an absolute reabsorption to the end of the proximal convolution of $15.5 \mathrm{nl} / \mathrm{min} \cdot \mathrm{Tf} / \mathrm{P}$ inulin ratio was 3.80 . The second population of tubules were widely dilated, had sluggish flow, and had markedly increased intratubular pressure. No accurate measurements could be made in these tubules since they collapsed with a rush of fluid into the collecting pipette as soon as they were punctured. Furthermore, transit time could not be measured in these nephrons since Lissamine green entered them slowly and without a clear wave of appearance or disappearance.

Proximal tubular pressure was unaltered in aminonucleoside animals $(12.1 \pm 0.2$ in 18 observations) when compared with controls ( $11.8 \pm 0.1$ in 16 observations) when normal sized tubules were tested. Dilated tubules had elevated pressures but they could not be measured by the manometric method available since they collapsed promptly after puncturing. Transit time to the end of the proximal convolution was markedly prolonged in aminonucleoside animals, averaging $16.7 \mathrm{sec}$ in 4-day and $18.6 \mathrm{sec}$ in 6day rats, whereas control transit times averaged $10.3 \mathrm{sec}$. All transit times were measured during the quantitative fluid collection during the free flow and in the same tubule.

\section{DISCUSSION}

The diminished sodium excretion observed in aminonucleoside nephrosis is undoubtedly due to a complex interaction of multiple factors. Urinary sodium may fall before the appearance of hypo- 
Table 2. Individual observations in late proximal convolutions

\begin{tabular}{|c|c|c|c|c|}
\hline & $\begin{array}{l}\text { SN GFR, }{ }^{1} \\
\mathrm{~m} \mu \mathrm{l} / \mathrm{min}\end{array}$ & $\begin{array}{l}\text { Absolute reabsorption, } \\
\mathrm{nl} / \mathrm{min}\end{array}$ & $\mathrm{Tf} / \mathrm{P}$ inulin & Transit time, sec \\
\hline \multicolumn{5}{|l|}{ A. Control } \\
\hline \multirow[t]{4}{*}{1} & 30.2 & 9.2 & 1.44 & 13.8 \\
\hline & 32.5 & 19.5 & 2.50 & 11.0 \\
\hline & 37.4 & 14.5 & 1.63 & 8.8 \\
\hline & 37.6 & 19.6 & 2.09 & 11.0 \\
\hline \multirow[t]{2}{*}{2} & 37.8 & 22.8 & 2.52 & 9.6 \\
\hline & 56.6 & 28.6 & 2.07 & 11.1 \\
\hline \multirow[t]{2}{*}{3} & 37.0 & 12.0 & 1.48 & 8.4 \\
\hline & 38.5 & 16.5 & 1.75 & 8.7 \\
\hline \multirow[t]{3}{*}{4} & 23.7 & 12.6 & 2.15 & 12.2 \\
\hline & 17.9 & 8.9 & 1.99 & \\
\hline & 24.7 & 6.7 & 1.37 & 9.8 \\
\hline \multirow[t]{2}{*}{5} & 23.5 & 6.5 & 1.38 & 9.6 \\
\hline & 25.7 & 8.7 & 1.51 & 9.2 \\
\hline \multirow[t]{2}{*}{ Mean $\pm \mathrm{SE}$} & $32.6 \pm 2.8^{2}$ & $14.3 \pm 1.9$ & $1.84 \pm 0.11$ & $10.3 \pm 0.5$ \\
\hline & $\pm 4.5^{3}$ & \pm 3.1 & \pm 0.18 & \pm 0.8 \\
\hline \multicolumn{5}{|c|}{ B. Aminonucleoside $(92-96 \mathrm{hr})$} \\
\hline \multirow[t]{4}{*}{ a. } & 30.5 & 19.5 & 2.77 & 20.0 \\
\hline & 34.8 & 24.8 & 3.48 & 15.0 \\
\hline & 25.3 & 13.3 & 2.11 & 12.0 \\
\hline & 34.7 & 21.7 & 2.67 & \\
\hline \multirow[t]{4}{*}{ b. } & 32.0 & 25.0 & 4.57 & 16.4 \\
\hline & 37.0 & 25.0 & 3.08 & 19.0 \\
\hline & 22.8 & 14.8 & 2.85 & 16.6 \\
\hline & 28.7 & 17.7 & 2.61 & 13.4 \\
\hline c. & 15.9 & 10.9 & 3.18 & 22.2 \\
\hline \multirow[t]{2}{*}{ d. } & 9.1 & 6.1 & 2.95 & 26.0 \\
\hline & 9.1 & 5.0 & 2.22 & 28.2 \\
\hline \multirow[t]{2}{*}{ e. } & 13.5 & 7.9 & 2.41 & 9.0 \\
\hline & 24.0 & 14.5 & 2.53 & 12.3 \\
\hline \multirow[t]{3}{*}{ f. } & 13.9 & 7.6 & 2.20 & 11.8 \\
\hline & 27.5 & 16.4 & 2.48 & 13.0 \\
\hline & 27.4 & 15.5 & 2.30 & 10.0 \\
\hline \multirow[t]{2}{*}{ g. } & 23.3 & 10.5 & 1.82 & 17.0 \\
\hline & 25.7 & 11.9 & 1.86 & \\
\hline \multirow[t]{4}{*}{ h. } & 9.0 & 5.4 & 2.49 & 18.0 \\
\hline & 6.6 & 4.7 & 3.45 & 21.0 \\
\hline & 14.7 & 9.1 & 2.63 & 12.4 \\
\hline & 13.3 & 8.3 & 2.66 & 19.0 \\
\hline \multirow[t]{2}{*}{ i. } & 18.4 & 13.0 & 3.41 & 14.8 \\
\hline & 18.9 & 15.5 & 5.57 & 21.2 \\
\hline \multirow[t]{2}{*}{ Mean $\pm \mathrm{SE}$} & $21.5 \pm 1.9$ & $13.5 \pm 1.3$ & $2.85 \pm 0.17$ & $16.7 \pm 1.1$ \\
\hline & \pm 3.1 & \pm 2.1 & \pm 0.28 & \pm 1.8 \\
\hline \multicolumn{5}{|c|}{ C. Aminonucleoside (142-144 hr) } \\
\hline \multirow[t]{3}{*}{ j. } & 14.0 & 8.5 & 2.57 & 18.6 \\
\hline & 20.5 & 15.5 & 4.17 & 14.0 \\
\hline & 35.8 & 23.7 & 2.96 & 11.8 \\
\hline
\end{tabular}


Table 2-Continued

\begin{tabular}{|c|c|c|c|c|}
\hline & $\begin{array}{l}\mathrm{SN} \mathrm{GFR}_{,}{ }^{1} \\
\mathrm{~m} \mu \mathrm{l} / \mathrm{min}\end{array}$ & $\begin{array}{c}\text { Absolute reabsorption, } \\
\mathrm{nl} / \mathrm{min}\end{array}$ & $\mathrm{Tf} / \mathrm{P}$ inulin & Transit time, sec \\
\hline \multirow[t]{4}{*}{ k. } & 33.1 & 24.8 & 3.99 & \\
\hline & 28.9 & 21.0 & 3.64 & 8.9 \\
\hline & 26.6 & 16.9 & 2.75 & 12.0 \\
\hline & 32.6 & 21.4 & 2.90 & 9.2 \\
\hline \multirow[t]{2}{*}{1.} & 30.9 & 25.3 & 5.56 & 16.4 \\
\hline & 35.6 & 29.4 & 5.75 & 19.2 \\
\hline \multirow[t]{3}{*}{$\mathrm{m}}$. & 18.0 & 11.4 & 2.70 & 15.8 \\
\hline & 21.0 & 12.0 & 2.34 & \\
\hline & 16.1 & 9.8 & 2.55 & \\
\hline \multirow[t]{2}{*}{ n. } & 20.2 & 14.2 & 3.34 & 24.0 \\
\hline & 10.8 & 8.2 & 4.13 & 21.8 \\
\hline \multirow[t]{2}{*}{ o. } & 20.1 & 15.8 & 4.68 & 27.2 \\
\hline & 13.7 & 9.6 & 3.36 & 17.8 \\
\hline \multirow[t]{2}{*}{ p. } & 28.0 & 19.3 & 3.22 & \\
\hline & 13.7 & 9.1 & 2.98 & \\
\hline$q$. & 14.8 & 11.2 & 4.11 & 24.8 \\
\hline \multirow[t]{3}{*}{ r. } & 8.7 & 6.6 & 4.16 & 24.3 \\
\hline & 16.9 & 13.0 & 4.34 & 27.2 \\
\hline & 21.8 & 16.6 & 4.19 & 15.8 \\
\hline \multirow[t]{3}{*}{ s. } & 12.1 & 9.1 & 4.03 & 24.8 \\
\hline & 15.9 & 12.6 & 4.83 & 22.4 \\
\hline & 21.3 & 15.1 & 3.44 & 14.8 \\
\hline \multirow[t]{3}{*}{ t. } & 25.7 & 19.4 & 4.05 & 19.2 \\
\hline & 26.0 & 19.7 & 4.13 & 16.2 \\
\hline & 19.6 & 15.0 & 4.25 & 20.6 \\
\hline \multirow[t]{2}{*}{ Mean $\pm \mathrm{SE}$} & $21.4 \pm 1.4$ & $15.5 \pm 1.1$ & $3.80 \pm 0.16$ & $18.6 \pm 1.1$ \\
\hline & \pm 2.2 & \pm 1.8 & \pm 0.26 & \pm 1.8 \\
\hline
\end{tabular}

${ }^{1}$ Single nephron glomerular filtration rate.

${ }^{2}$ Each number represents one observation in one tubule.

${ }^{3}$ Standard error using $\mathrm{N}$ as number of animals.

proteinemia. Glomerular filtration rate is decreased significantly in this disease and, unless compensated for by a decrease in tubular reabsorption, will lead to decreased sodium excretion. Under most circumstances changes in glomerular filtration rate are accompanied by proportional changes in proximal tubular absolute reabsorption so that fractional reabsorption remains unchanged. However, in these animals, studied 4 or 6 days after the injection of aminonucleoside, decreases in glomerular filtration rate are not accompanied by proportional decreases in absolute reabsorption. The resulting increase in fractional reabsorption is reflected by the elevated $\mathrm{Tf} / \mathrm{p}$ inulin ratios.

In the animals studied 4 days after AMN injection, surface nephron GFR is decreased to a greater degree than overall GFR. This suggests that there may be a changed distribution of filtrate with the deeper nephrons contributing a greater proportion of overall filtration. In the animals studied 6 days after injection, the problem is complicated by a marked heterogeneity of nephrons. Many surface nephrons are dilated and are non-functional or minimally functional. Thus, only the normal appearing nephrons were available for measuring physiologic parameters. These were quite similar to the findings in late proximal tubules in early AMN rats. The striking reduction in overall GFR at 6 days un- doubtedly reflects the large population of non- or minimally functional nephrons. It should be noted that Oken et al. (18), in a recent micropuncture study, found no difference in $\mathrm{Tf} / \mathrm{P}$ inulin ratios in randomly punctured tubules in control rats and in rats studied 4 days after the injection of aminonucleoside. The reason for this difference in not clear. One possibility, however, concerns the selection of tubules for micropuncture. All measurements of absolute reabsorption and $\mathrm{Tf} / \mathrm{P}$ inulin ratios in this study were made in the late proximal tubules. Oken et al. specifically excluded any nephrons in which they could not collect $40 \mathrm{nl}$ within $5 \mathrm{~min}$. This was done in order to reduce the risk of extraneous albumin contamination. Since proximal tubular flow is diminished in the AMN rats, this would tend to favor collections from mid- and early proximal tubules which would in turn lower the mean Tf/P inulin ratio of an otherwise random selection of tubules.

In the present study absolute reabsorption to the end of the proximal convolution is unaltered in AMN rats despite the pressence of a number of circumstances usually associated with decreased proximal fluid reabsorption. Earley et al. $(4-6,16)$ have suggested that in a number of experimental and clinical conditions changes in reabsorption may result from changes in 
either peritubular colloid oncotic or hydrostatic pressure. Lewy and Windhager (14) have demonstrated changes in reabsorptive activity of proximal tubules proportional to changes in filtration fraction. Brenner et al. ( $1-3)$ and Spitzer and Windhager (21) have shown that direct changes in colloid oncotic pressure lead to changes in absolute reabsorption. Increased peritubular colloid oncotic pressure leads to increased proximal tubular fluid reabsorption and decreased peritubular colloid oncotic pressure to decreased reabsorption. In the present study filtration fraction was significantly decreased in the aminonucleoside animal, a circumstance that would be expected to lead to a decrease in absolute reabsorption. In addition, plasma protein concentration is decreased in the 6-day AMN rats, which might also lead to a diminished peritubular colloid oncotic pressure.

The reason for the failure of absolute reabsorption to be decreased in the proportion to the decrease in GFR in the presence of a number of natriuretic conditions can only be speculated upon at present. One possibility is that there might be an internal redistribution of blood flow or glomerular filtrate. Clearance of PAH as measured in this study is the whole kidney clearance of PAH. Thus, the filtration fraction calculated from overall clearance of inulin and of $\mathrm{PAH}$ reflects the filtration fraction for the whole kidney. Because all tubular punctures were performed on surface proximal convolutions, it is possible that the filtration fraction of surface nephrons may have differed from that in the juxtamedullary nephrons. The dilated tubules in the rats studied 6 days after aminonucleoside injection had extremely low flow and unmeasurable GFR. The filtration fraction for the dilated nephrons must thus be extremely low or in some cases, 0 . The filtration fraction for the normal sized tubules is likely therefore to be unaltered from controls or even elevated. Overall filtration fraction is thus a poor estimate of individual nephron filtration fraction in this model.

Changes in hydrostatic pressure gradients are not revealed by measurements of intratubular pressure in normal sized tubules. However, since the linear velocity of flow was diminished in the proximal tubules of aminonucleoside animals (as reflected by the passage time) and since volume flow was decreased (as reflected by individual nephron GFR), it is apparent that the proximal tubular radius was not decreased in proportion to the reduction in volume flow. Since intratubular pressure was not increased, this might suggest a change in the compliance of the tubular wall or in peritubular capillary pressure.

Another factor that might influence reabsorption would be a change in hydraulic conductance of the tubular or peritubular barrier. An increased permeability of the peritubular capillary wall might lead to increased net reabsorption at any given level of balance of Starling forces. Hypovolemia, if present, might result in decreased peritubular hydrostatic pressure which would favor increased reabsorption. No direct measurements of peritubular pressure were made during this study to assess that possibility.

\section{SUMMARY}

The data indicate that in early aminonucleoside nephrosis (4 day), glomerular filtration rate is diminished. This is associated with an unchanged clearance of $\mathrm{PAH}$ and intratubular pressure. Absolute rates of fluid reabsorption to the end of the proximal convolution are unaltered. A decreased glomerular load, associated with an unaltered absolute rate of fluid reabsorption, leads to increased fractional reabsorption of solute and water. In rats with fully developed AMN nephrosis (6 day), marked nephron heterogeneity is apparent. Many nephrons are dilated and minimally or nonfunctional. Those which remain normal in appearance have decreased GFR but unaltered rates of absolute fluid reabsorption and increased fractional reabsorption. GFR reduc- tion and redistribution of filtrate or blood flow as well as locally increased filtration fraction may contribute to the genesis of edema in this model. Other complex and unresolved factors surely also come into play as the disease progresses.

\section{REFERENCES AND NOTES}

1. Brenner, B. M., Bennett, C. M., and Berliner, R. W.: The relationship between glomerular filtration rate and sodium reabsorption by the proximal tubule of the rat nephron. J. Clin. Invest., 47: 1358 (1968).

2. Brenner, B. M., Falchuk, K. H., Keimowitz, R. I., and Berliner, R. W.: The relationship between peritubular capillary protein concentration and fluid reabsorption by the renal proximal tubule. J. Clin. Invest., 48: 1519 (1969).

3. Brenner, B. M., and Troy, L.: Postglomerular vascular protein concentration: Evidence for a causal role in governing fluid reabsorption and glomerulotubular balance by the renal proximal tubule. J. Clin. Invest., 50: 336 (1971).

4. Earley, L. E., and Daugharty, T. M.: Sodium metabolism. N. Engl. J. Med., 281: 72 (1969).

5. Earley, L. E., and Friedler, R. M.: The effects of combined renal vasodilatation and pressor agents on renal hemodynamics and the tubular reabsorption of sodium. J. Clin. Invest., 45: 542 (1966).

6. Earley, L. E., Martino, J. A., and Friedler, R. M.: Factors affecting sodium reabsorption by the proximal tubule as determined during blockage of distal sodium reabsorption. J. Clin. Invest., 45: 1668 (1966).

7. Frenk, S., Antonowicz, I., Craig, J. M., and Metcoff, J.: Experimental nephrotic syndrome induced in rats by aminonucleoside: Renal lesions and body electrolyte composition. Proc. Soc. Exp. Biol. Med., 89: 424 (1955).

8. Godon, J. P.: Sodium and water retention in experimental glomerulonephritis. Kidney Intern., 2: 271 (1972).

9. Goldring, W., and Chassis, H.: Hypertension and hypertensive disease. Appendix D: Methods, p. 194 (The Commonwealth Fund, New York, 1944).

10. Gottschalk, C. W., and Mylle, M.: Micropuncture study of pressures in proximal tubules and peritubular capillaries of the rat kidney and their relation to ureteral and renal venous pressures. Amer. J. Physiol., I85:430 (1956).

11. Herkin, H., Senft, G., and Von Stuckrad, H.: Die Stoerungen der Nierenfunktion nach einwirkung von aminonucleosid. Naunyn-Schmiedeberg's Arch. Exp. Pathol., 240: 394 (1961).

12. Kalant, N., Das Gupta, D., Despointes, R., and Giroud, C. J.: Mechanisms of edema in experimental nephrosis. Amer. J. Physiol., 202: 91 (1962).

13. Lewy, J. E., and Pesce, A. J.: Micropuncture study of albumin transfer in aminonucleoside nephrosis in the rat. Pediat. Res., 7: 553 (1973).

14. Lewy, J. E., and Windhager, E. E.: Peritubular control of proximal tubular fluid reabsorption in the rat kidney. Amer. J. Physiol., 214: 943 (1968).

15. Lowry, O. H., Rosebrough, N. J., Farr, A. L., and Randall, R. J.: Protein measurement with the Folin phenol reagent. J. Biol. Chem., 193: 265 (1951).

16. Martino, J. A., and Earley, L. E.: Demonstration of a role of physical factors as determinants of the natriuretic response to volume expansion. J. Clin. Invest., 46: 1963 (1967).

17. Metcoff, J., and Janeway, C. A.: Studies on the pathogeneis of nephrotic edema. J. Pediat., 58: 640 (1961).

18. Oken, D. E., Cotes, S. C., and Mende, C. W.: Micropuncture study of tubular transport of albumin in rats with aminonucleoside nephrosis. Kidney Intern., 1: 3 (1972).

19. Rector, F. C., Brunner, F. P., Sellman, J. C., and Seldin, D. W.: Pitfalls in the use of micropuncture for the localization of diuretic action. Ann. N. Y. Acad. Sci., 139: 400 (1966).

20. Rocha, A., Marcondes, M., and Malnic, G.: Micropuncture study in rats with experimental glomerulonephritis. Kidney Intern., 3: 14 (1973).

21. Spitzer, A., and Windhager, E. E.: Effect of peritubular oncotic pressure changes on proximal tubular fluid reabsorption. Amer. J. Physiol., 218: $1188(1970)$.

22. Steinhausen, M.: Eine Methode zur Differenzierung proximaler and distaler Tubuli der Nierenrinde von Ratten in vivo und ihre Anwendung zur Bestimmung tubularer Stroemungsgeschwindigkeiten. Pflueger's Arch. Ges. Physiol., 277: 23 (1963).

23. Surtshin, A.: Influence of adrenals on edema in nephrotic syndrome [Abstract]. Fed. Proc., 17: 158 (1958).

24. Yoshida, T., and Metcoff, J.: A metabolic basis of aminonucleoside nephrosis. Effect of aminonucleoside (AMN) on oxidative phosphorylation (OP) at the substrate level [Abstract]. J. Pediat., 67: 917 (1965).

25. Vernier, R. L., Papermaster, B. W., and Good, R. A.: Aminonucleoside nephrosis. I. Electron microscopic study of the renal lesion in rats. J. Exp. Med., 109: 115 (1959).

26. Wirz, H.: Druckmessung in Kapillaren und Tubuli der Niere durch Micropunktion. Helv. Physiol. Pharmacol. Acta, 13: 42 (1955).

27. This research was supported in part by National Institutes of Health Grant no. AM 14869.

28. Requests for reprints should be addressed to: J. E. Lewy, M.D., Division of Pediatric Nephrology, Department of Pediatrics, Cornell University Medical College, New York, N.Y. 10016 (USA).

29. Accepted for publication August 15, 1975. 